\title{
Public Management Mentoring: What Affects Outcomes?
}

\author{
Barry Bozeman \\ University of Georgia \\ Mary K. Feeney \\ University of Illinois-Chicago
}

\begin{abstract}
Few research studies focus on public managers' mentoring, and few mentoring studies include any outcome measure other than reported satisfaction. Our study examines diverse outcomes for a broad-based set of public managers, including not only satisfaction but also the number of employees supervised in the current job, whether the most recent job was a promotion, and whether the protégé is now a mentor. We argue that these may be particularly important outcomes in the public sector due to the common basis of promotion in numbers supervised and due to the special need to develop protégés into mentors. Our findings show that mentoring outcomes are predicted by attributes of the protégé, the mentor, and the mentoring relationship and by the degree and type of social capital focus of the mentoring.
\end{abstract}

\section{INTRODUCTION}

Mentoring programs abound in both public and private organizations and the value of these programs to the individual and to the organization often is taken as an article of faith. The fact that mentoring occurs just as often "organically," without either the imprimatur of an organization or the structure provided by a formal program, tells us that mentoring is more than an organizational imperative, rather it is a social relationship pursued by individuals expecting returns to their careers and to their human and social capital. But are the expectations of organizations, mentors, and protégés realized? Despite a proliferation in mentoring studies (see Bozeman and Feeney 2007 for an overview), few focus on the career outcomes of mentoring relationships and even fewer examine outcomes other than perceived satisfaction with the mentor. Systematic research on mentoring in a public sector setting represents only a small fraction of all mentoring studies and most of these include no career outcome variables.

\footnotetext{
The authors are grateful to those who have sponsored, developed, or managed the National Administrative Studies Project-III, including Branco Ponomariov, Craig Boardman, Hal Rainey, Gordon Kingsley, Julia Melkers, and Eric Welch. Address correspondence to the author at bbozeman@uga.edu.
} 
Public sector agencies seem especially anxious to promote mentoring. A number of factors underlie this public sector emphasis on mentoring. In part the motivation is demographic. The public sector faces new challenges as the workforce ages at the same time as the demand for higher skill and education levels is increasing. The growing demand and decreasing supply of skilled workers makes it more difficult for the public sector to attract and retain talented workers who may choose private sector work due to better compensation or opportunities for advancement (Johnston and Packer 1987).

Many mentoring programs aim to build the public sector by providing additional training for managers, especially women and minorities. The U.S. Office of Personnel Management argues that mentoring enables agencies and managers to develop women in federal positions $(1998,14)$. Although public resources are used to initiate mentoring programs, with the goals of retaining employees and increasing diversity in management, there is little research focusing on the outcomes of public sector mentoring.

The vast majority of research on mentoring is "generic," assuming that the institutional context matters little. Very little research (Fox and Schuhmann 2001; Kelly et al. 1991; Klauss 1981) focuses on public managers and examines the distinctive political environments affecting public managers' mentoring. Mentoring research has overwhelmingly focused on samples of executives in private organizations (Collins 1978; Roche 1979), managers in high-technology manufacturing firms (Scandura 1992; Scandura and Schriesheim 1994), university alumni (Chao et al. 1992), professional association members (Ragins et al. 2000), and accountants (Eby and Allen 2002; Scandura and Ragins 1993; Scandura and Viator 1994). Numerous studies examine mentoring in academic settings, often using samples of graduate students in business administration (Godshalk and Sosik 2003; Tepper 1995), faculty (Green and Bauer 1995; Young and Perrewe 2000), or university administrators (Bozionelos 2004).

Our research aims to expand the empirical research on mentoring in the public sector. We consider a number of outcomes pertaining to mentoring, including the number of employees currently supervised, whether the current job was a promotion, and whether the protégés have themselves become mentors to others. The focus on these outcomes represents a departure from traditional emphasis of private sector mentoring on the relation of mentoring to financial rewards. Although financial rewards may in some cases be appropriate targets for public sector studies, in many instances salary is determined less by performance than tenure and seniority.

A distinctive feature of our study is that in considering mentoring outcomes, we focus on the important role mentors play in introducing protégés to influential persons within and outside the organization and, in general, expanding the protégé's professional network (Friedkin 1978). Whereas many (e.g., Hezlett and Gibson 2007) recognize the importance of contacts, networks, and social capital in mentoring, few studies (Eby et al. 2006; van Emmerik 2006; ) have empirically examined this important aspect of mentoring.

Whereas some researchers (Green and Bauer 1995; Russell and Adams 1997) express the need for studies of the impact of mentoring on career advancement, political and social skills, organizational citizenship, or supervisory responsibility, most continue to focus on measures of protégé satisfaction. We seek to begin to fill these gaps in the mentoring and public management literatures by focusing on a diverse set of mentoring outcomes. Below, we summarize relevant literature on mentoring outcomes. 


\section{MENTORING OUTCOMES}

The majority of studies of mentoring outcomes focus exclusively on perceptions. Although there have been studies of more tangible outcomes such as job mobility (Scandura 1992) and career progress (Bozionelos 2004; Fagenson 1989), most outcomes-oriented studies focus on perception-based dependent variables such as job satisfaction and organizational commitment (Aryee and Chay 1994; Heimann and Pittenger 1996). Given the abundance of research on mentoring, one assumes that favorable outcomes must accrue, otherwise why are so many individuals actively involved? But are those "favorable outcomes" more akin to placebo effects or does mentoring result in career advancement and improved human capital?

Generally, our expectations about mentoring outcomes are drawn from previous research findings when such findings are available and indirectly relevant public management research findings when there are no directly relevant studies. We consider four protégé outcomes: satisfaction with the mentorship, the number of employees supervised, promotion, and whether one who has been a protégé has become a mentor. Since there are few broad-based studies of public management mentoring outcomes suggesting directly relevant previous findings, we do not specify different hypotheses for different outcomes. We recognize, of course, that the various outcomes have quite different implications not only in their favorableness but also in the details of their causal mechanics. But at this point we are content to view each as a "positive outcome" and to employ a generalized outcome hypothesis.

We expect that positive mentoring outcomes will be a function of four interrelated categories of variables: protégé attributes, mentor attributes, mentorship characteristics, and the social capital focus of the mentoring. Like Bourdieu (1985), we define social capital as the aggregation of networks of highly institutionalized and less formal relationships and acquaintances (p. 248). Accordingly social capital, as monetary capital, is the result of individual investment and participation in relationships. By defining social capital as a condition of use of the resources available in social networks (Burt 1997, 2000; Coleman 1988; Lin 1999), the social capital resulting from a mentoring relationship will be determined by the relationship's ability to provide access to quality social network resources.

Relationships with mentors and protégés increase an individual's social network affiliations and can enhance communication and increase access to additional information (Loury 1977). These relationships can also create social capital through reciprocity expectations and enforcement of norms (Coleman 1988). Mentors can exert influence on protégé careers by increasing information about hiring and promotion and connecting protégés with other influential people and resources within their own social networks (Lin 1999). We assume that social capital is not a guaranteed outcome of mentoring, or any relationship, but when it is available it is a resource individuals can use to secure benefits for personal or group gain (Baker 1990, p. 619; Lin 1999; Portes 1998).

The social capital focus of the mentoring relationship is dictated in part by the attributes of the protégé, mentor, and the mentorship. In particular, protégés who have high levels of motivation and external social capital (an indication of a propensity to interact and engage in boundary spanning) will be high-demand protégés and, thus, will receive more social capital opportunities. All else equal, we can expect that mentors will tend to choose "quality" protégés and vice versa. However, in formal mentoring program, 
as compared to more organic informal mentoring, choice tends to be constrained. Formal programs employ diverse mentor-protégé selection criteria, such as, for example, geographic or organizational location, and perceived quality may not be prominent among the choice criteria.

Below, we present our hypotheses and, when possible, ground them the relevant literature pertaining to those hypotheses. Most of the literature employed below is only indirectly related; few of these studies examine the outcome variables we use and even fewer are empirical studies of public managers.

\section{HYPOTHESES}

We expect that protégé attributes, in particular protégé work motivation, will have strong effects on mentoring outcomes. Presumably, mentors are more willing to invest in highly motivated protégés and, likewise, protégés with high work motivation are more likely to exploit the opportunities available in the mentoring relationship.

Our hypothesis that mentor perception of a "high-quality" protégé will increase social capital outcomes is somewhat novel to the mentoring literature, though the notion that perceptions and expectations influence outcomes is not. Mentor and protégé perceptions are related to relationship effectiveness and trust (Young and Perrewe 2000), and protégés with high levels of learning goal orientation, similar to the mentor, report higher levels of career satisfaction and attained managerial aspirations (Godshalk and Sosik 2003). This leads us to predict that the perception that a protégé is above average will act as an incentive for the mentor to invest in the relationship and increase the protégé's access to social networks and capital. The protégé's work motivation may be an important component of perceived protégé quality and, thus, we examine the hypothesis below.

$\mathrm{H}_{1} \quad$ More positive mentoring outcomes will tend to be associated with protégés who have higher work motivation.

Second, we expect that mentor attributes will affect mentoring outcomes, whether the mentor is inside or outside the protégé's organization. Some of these effects are indirect. For example, it is likely that longer standing or older relationships will be with mentors outside the focal organization (since it is likely that the mentor, protégé, or both have gone on to jobs in different organizations). But we also expect more direct effects because the nature of the social capital imparted will differ (i.e., outside mentors will have difficulty imparting social capital pertaining to the focal organization).

Though the mentoring literature says little about the role of mentors according to whether the mentors are internal or external to the protégés organization (Baugh and Fagenson-Eland 2004; Eby 1997), it makes sense that a mentor in the same organization as the protégé will differently affect career outcomes than a mentor in a different organization. A protégé may report having a mentor outside of the organization for many reasons. The mentor and protégé may have met in a previous organization, the mentor may have retired, or the protégé may have moved to a new organization. A protégé with a mentor in the same organization may be in a new mentorship or a formal program where the organization assigned the mentor to the protégé. Of course, organizations with formal mentoring programs will match mentors and protégés within the same organization, thus ensuring that mentorship outcomes accrue to the mentor, the protégé, and the organization. 
External mentors may be responsible for increasing the protégé's social capital outside of the organization, introducing the protégé to influential people or new employment opportunities outside of the protégé's current organization. Internal mentors, on the other hand, are more likely to help the protégé navigate the organization in which they both work. This assistance may come in the form of assigning the protégé challenging tasks, introducing the protégé to influential people within the organization, or recommending the protégé for a promotion. Furthermore, because mentors and protégés in the same organizations are likely to have more frequent contact, we expect increased outcomes for mentorships in which the protégé and mentor are contemporaneously members of the same work organization.

$\mathrm{H}_{2}$ More positive mentoring outcomes will tend to be associated with mentors being in the same organization as the protégé's current organization.

We expect that mentoring outcomes will be shaped by the composition of the mentorship such as the gender match of protégé and mentor, the duration and origin (formal or informal) of the mentorship, and the social capital focus of the mentorship. The mentoring literature is inconclusive on the effects of protégé and mentor genders on outcomes. Though some researchers hypothesize that women will benefit from having mentors of the same gender (Berg and Ferber 1983; Gilbert 1985), it is common for female protégés to pair with male mentors due to limited access to female mentors and the perception that a male mentor will provide easier entry into the "old boy's network" in male-dominated occupations (Ragins 1989; Ragins and McFarlin 1990; Thomas 1990; Thomas and Alderfer 1989).

Although there are concerns about the potential for abuse and harassment in crossgender relationships (Auster 1984; Hurley and Fagenson-Eland 1996; Ragins 1997a, 1997b), research indicates that women are more likely to be in cross-gender mentoring dyads and are not more likely than males to be in abusive mentoring relationships (Burke and McKeen 1997; Ragins and Scandura 1997). In fact, mentors in cross-gender dyads report that their protégés used the mentorship more effectively than same-gender mentors reported for their protégés (Noe 1988). Noe suggests that this may be the result of protégés in cross-gender dyads making conscious or unconscious attempts to ensure the success of the relationship due to perceptions and stereotypes that cross-gender mentorships are vulnerable to negative outcomes. It is possible that a female protégé assigned to a male mentor perceive the formal program as their only opportunity to find a good mentor, and therefore are more eager to make that relationship successful (Noe 1988). Still, we favor Ragin's (1997) theory that homogenous dyads produce more favorable outcomes than heterogeneous dyads because a gender match is likely to facilitate a broader, more multifaceted relationship.

$\mathrm{H}_{3}$ More positive mentoring outcomes will tend to be associated with relationships in which the genders are matched (i.e., male and male, female and female).

In addition to the gender composition, we expect that the duration of the mentoring relationship will be related to positive outcomes. The longer mentoring relationships offer more opportunities for increasing outcomes and extending social networks as both the protégé and the mentor acquire larger individual and shared networks. In addition, mentoring relationships that last for a longer period of time represent relationships, which both the mentor and the protégé have chosen to continue, most likely because they continue to benefit from the relationship. Likewise, short-term mentoring relationships may represent 
failed mentorships or lower levels of motivation on the part of one or both members of the dyad. It seems plausible that those who are not receiving favorable outcomes would be likely to terminate the relationship. Although this is not a logical necessity, it seems apparent that some minimal threshold of time is required for any sort of outcomes.

In general, most empirical mentoring research controls for duration of mentoring, but few researchers analyze or highlight this as a variable of interest (Godshalk and Sosik 2003; Ragins and McFarlin 1990). Those that address mentoring duration and outcomes find mixed results. In their survey of 24 mentors and 87 protégés (response rate of $90 \%$ ), Fagenson-Eland, Marks, and Amendola (1997) find that an increase in mentorship duration is significantly related to psychosocial outcomes and speculate that career-related benefits may take more time to achieve than psychological benefits. In contrast, Ragins and McFarlin (1990) report that longer mentoring relationships do not result in increased perceptions of mentoring benefits among protégés. The inconsistent relationships between mentoring duration and outcomes may be driven by sample design. For example, Bozionelos (2004) limited his sample of 188 white-collar administrators in three universities (response rate $31.2 \%$ ) to mentoring relationships of at least 2 years with the explanation that other researchers (e.g., Chao 1997; Fagenson-Eland et al. 1997) have found this to be the base time needed for a mentor relationship to produce measurable outcomes, whereas Godshalk and Sosik (2003), in their survey of 217 full-time corporate employees enrolled in masters of business administration programs at a large public university in the Northeast who identified as protégés or mentors, included all mentoring relationships ranging from 1 to 15 years in duration. Given these limited and mixed results, we favor the notion that increased mentoring duration will increase mentoring outcomes.

$\mathrm{H}_{4}$ More positive mentoring outcomes will tend to be associated with mentorships of longer duration.

We expect that whether the mentoring relationship is developed informally or by formal "matchmaking" will be a major determinant of mentoring outcomes. The research literature comparing formal and informal mentoring is inconclusive, but we expect that, all else equal, informal mentoring relationships will be more likely to have positive outcomes simply because there is an obvious affinity. When there is such an affinity, perceptions are likely more positive and it is also likely that each party invests more in the mentoring relationship.

A great deal of mentoring research investigates the outcomes of formal and informal mentoring including socialization and commitment (Chao et al. 1992; Heimann and Pittenger 1996), psychosocial support, career guidance, role modeling, communication (Fagenson-Eland et al. 1997; Noe 1988), job satisfaction, and salary (Chao et al. 1992). Kram (1985) predicts that formal and informal mentoring will result in different outcomes because assigned relationships lack the personal chemistry and commitment necessary for success. In addition, formal mentoring may lead to mentor-protégé mismatch, uncomfortable relationships with minimal communication (Mullen 1994), and negative mentoring experiences resulting in increased protégé turnover and stress (Eby and Allen 2002).

Research on formal and informal mentoring has produced mixed results. In a study of formal mentorships between 139 educators (protégés) and 43 administrators (mentors), Noe (1988) found that protégés in formal mentorships reported larger psychosocial outcomes than career benefits. Using a sample of 764 (576 responses) alumni from a large Midwestern university $(n=373)$ and a small private institute $(n=203)$, Chao et al. (1992) found that both formally and informally assigned protégés compared to nonmentored 
individuals reported similar levels of psychosocial support. However, protégés in informal relationships reported higher organizational socialization, job satisfaction, and salaries compared to formally mentored and nonmentored individuals. Chao et al. (1992) conclude that assigned mentoring relationships may produce similar psychosocial outcomes, but not similar career outcomes because the formal assignment reduces mentor motivation and protégé openness.

In contrast to previous research, Fagenson-Eland et al. (1997) found that protégés in formal relationships reported less psychosocial outcomes than informally mentored protégés and no significant differences in career guidance outcomes. In addition, they found that formally assigned mentors reported less communication with their protégés compared to informal mentors. Tepper's (1995) study of 259 managerial and technical/professional employees found that informally mentored junior colleagues used distinctive patterns of communication and maintenance strategies with their supervisors (mentors) which were significantly different from strategies used by formally assigned protégés and nonmentored individuals. Informal mentorships seem to produce socialization and training that increases the protégé's ability to communicate with superiors (Tepper 1995) and increase the frequency of communication with mentors (Fagenson-Eland et al. 1997). Though research on formal mentoring remains mixed, like Kram (1985), we predict that assigned mentorprotégé relationships will less often be associated with positive outcomes than will relationships that develop informally.

$\mathrm{H}_{5}$ More positive mentoring outcomes will tend to be associated with informal mentorships.

Finally, although there are many aspects of social capital one might consider in mentoring, we are interested in, first, whether social capital is an important element of the mentorship and, second, in those cases where there is a social capital focus, determining if the focus is on making contacts within the focal organization, in organizations outside the focal organization, or both.

We assume that with respect to positive mentoring outcomes, more social capital is better. That is, those who have significant social capital both inside and outside the organization will have the most positive mentorship outcomes. We assume that those with social capital focused within the organization will tend to have somewhat higher positive mentoring outcomes than those who have only external social capital. Our reasoning is instrumental - internal social capital will be more easily appropriated by the protégé, leading to higher levels of satisfaction and practical use of information for promotion and advancement within the organization.

$\mathrm{H}_{6} \quad$ Mentoring outcomes will tend to be most positive for relationships in which both internal and external social capital are imparted, second most positive for relationships in which only internal social capital is imparted, third most positive for relationships in which only external social capital is imparted, and least positive for relationships in which no significant social capital is imparted.

\section{DATA SOURCES, VARIABLES AND STATISTICAL APPROACH}

Each of the hypotheses is operationalized with variables developed from the National Administrative Studies Project (NASP-III). The data were derived from 787 responses 
to mailed questionnaires sent to a random sample of 1853 state-level public managers, upper-level professionals, and technicians, in Georgia and Illinois. The response rate was 42\%, with 431 managers from Georgia and 356 from Illinois. Because we compare how mentor, protégé, and mentorship attributes affect outcomes, we focus on the 406 respondents who indicated they have had a mentor. The NASP-III study procedures and descriptive statistics are described more fully in Appendix 1 and 2 (also see Feeney [forthcoming]).

We note that the data are limited. In the first place, the data are not panel data nor longitudinal in any other respect, and the only time-related data are contemporaneous reports of previous events. In the second place, the sample response is typical for privately initiated and voluntary surveys of public employees, but is sufficiently low to raise concerns about possible response bias.

Although we are working with a sample of 406 respondents who reported being mentored, the $N$ size in the models is between 222 and 259. A missing variable analysis of all dependent and independent variables indicates that there are missing values for a number of variables, with an average of 15 missing responses (mode of 12) and a maximum of 70 missing responses for the variable of number of employees supervised (table 1). The missing values in these cases are driven by high-response difficulty for these survey items. ${ }^{1}$ For example, reporting the month and year a mentorship began and ended is a high-difficulty item and calculating mentorship duration required responses on each item.

We analyzed correlations of missing data dummy variables with a variety of demographic characteristics, including gender, job type, age, race, and state. None of these yielded correlations significant at the .10 level. Although these results are encouraging, they are not sufficient to rule out bias. One possible remedy is imputation. We considered multiple imputation approaches (Rubin and Schenker 1986), but we did not feel we could meet the assumption that missing data are "missing completely at random" (in the sense of Allison's [2001] phrase).

In sum, missing data remain a significant limitation and these results must be treated with caution. Due to possible bias related to missing data, we refrain from making casual claims and, instead, argue that our findings are suggestive and await further research.

\section{DEPENDENT VARIABLES}

We measure mentoring outcomes with four dependent variables (detailed descriptions of the variables are in Appendix 2). The first dependent variable, Satisfaction, is an additive scale created from three questionnaire items measuring the protégé's satisfaction with the mentorship. The scale measuring protégé satisfaction with the mentor includes three response categories: very satisfied, somewhat satisfied, and unsatisfied (a combination of somewhat and very dissatisfied response).

We include two dependent variables, which serve as indicators of career advancement in public organizations. The variable, \#Employees, is a self-reported interval-level variable

1 The NASP-III items asking about current and past job history had high difficulty. These items asked respondents to indicate the job title; organization name; sector of organization; type of promotion or lateral move; start date and end date of the position; manager, technician, or professional; and the number of employees supervised. Because of the high item difficulty and personal nature of the responses, many surveys were returned with missing values. We investigated nonresponse for these items and found that a majority of individuals cited item difficulty and not wanting to take the time to complete this portion of the survey. Fortunately, these missing values are randomly distributed throughout the dataset. 
Table 1

Missing Variable Analysis

\begin{tabular}{lcclrr}
\hline \multicolumn{1}{c}{ Variable } & $N$ & Missing & \multicolumn{1}{c}{ Variable } & Missing \\
\hline Civic activities & 406 & 0 & Mentor initiated & 385 & 21 \\
Security & 394 & 12 & Formal & 385 & 21 \\
Advance & 394 & 12 & Promotion & 406 & 0 \\
Endyear & 384 & 22 & Protégé-mentor & 395 & 11 \\
Female & 402 & 4 & Satisfaction with Mentor & 390 & 16 \\
SC-inside & 394 & 12 & Gender match & 397 & 9 \\
SC-outside & 395 & 11 & Internal & 400 & 6 \\
SC-both & 394 & 12 & \#Employees & 336 & 70 \\
Internal & 385 & 21 & & & \\
\hline
\end{tabular}

SC, social capital.

indicating the number of employees directly supervised by the respondent. Although the number of employees supervised is rarely considered in the generic mentoring literature, this measure is especially important in the public sector where pay and pay grade are often tied to the number of employees supervised, which can serve as a determinant of wages and position in the organizational hierarchy. Another advancement-related dependent variable, promotion, is a dummy variable coded one if respondent's current job was a promotion.

One possible outcome of a mentoring relationship is that the protégé, perhaps influenced by her experiences in the relationship, may engage in "role modeling" and become a mentor to another (Bozionelos 2004; Fagenson et al. 1997; Scandura and Viator 1994). This final dependent variable, Protégé-Mentor, is a dummy variable derived from responses to the questionnaire item "Have you ever been a mentor?" (yes =1).

\section{INDEPENDENT VARIABLES}

The measures of protégé work motivation were developed from a factor analysis of work motivation variables. The variables security motivation and advancement motivation were developed from responses to five questionnaire items about respondents' motivations for taking their current job (see table 2 for a full description of these responses). The factor analysis of these five questionnaire items resulted in the two dimensions, for convenience labeled Security and Advancement, which together represent $60.5 \%$ of the common variance in the initial correlation matrix. The factor loadings matrix is presented in table 2 . We used the computed factor scores as independent variables. Cronbach's alpha calculations (.78) show that the dimensions are within acceptable range of reliability, especially for a short scale. ${ }^{2}$

The measure for colocation of the mentor and the protégé is a dummy variable, External, coded one if the mentor is in an organization other than the protégé's organization and zero if the mentor is in the same organization as the protégé. The variables

2 As a general rule of thumb, most analysts consider .70 an adequate Cronbach's alpha. However, the requisite size is a function of the length of the scale. Since Cronbach's alpha mimics results from a one factor solution in an unrotated principal components factor analysis solution (assuming roughly equal covariances) the use of alpha for all the factors in a two factor solution suggests that different assumptions are appropriate. As reported in table 2, the alpha for all the variables in the factor analysis is .68. However, a more appropriate criterion is for the first factor (since, by implication, the second orthogonal factor will include variables not strongly correlated with those in the first). The alpha for the variables defining this dimension (those loading \pm .50 ) is .78 . 
Table 2

Motivation for Taking Current Job Factor Loadings for Security Motivation and Advancement Motivation

\begin{tabular}{|c|c|c|}
\hline \multirow[b]{2}{*}{ Questionnaire item } & \multicolumn{2}{|c|}{ Factor } \\
\hline & Security motivation & Advancement motivation \\
\hline Advance in organizational hierarchy & .195 & .593 \\
\hline Job security & .608 & .120 \\
\hline Pension or retirement plan & .751 & .202 \\
\hline Desire increased responsibility & -.040 & .723 \\
\hline Benefits (medical, insurance) & .816 & .192 \\
\hline Few, if any, alternative job offers & .198 & -.053 \\
\hline Eigenvalue & 2.34 & 1.29 \\
\hline Percent of variance & $39.1 \%$ & $21.4 \%$ \\
\hline \multicolumn{3}{|c|}{$\begin{array}{l}\text { Note: Orthogonal solution, varimax rotation, using SPSS v.13. Interpretation focuses specifically on factor loadings that are equal to } \\
\text { or greater than } \pm .50 \text {. Cronbach's alpha for six variables }=.68 ; .78 \text { for first factor variables loading in excess of } \pm .50 \text {. NASP-III gave } \\
\text { respondents the following directive: We are interested in the factors that motivated you to accept a job at your current organization. } \\
\text { Please indicate the extent to which the factors below (some personal, some family, some professional) were important in making your } \\
\text { decision to take a job at your current organization: (1) opportunity for advancement within the organization's hierarchy; (2) the } \\
\text { organization's pension or retirement plan; (3) desire for increased responsibility; (4) benefits (medical, insurance); and (5) few, if any, } \\
\text { alternative job offers. Likert response categories: strongly agree, somewhat agree, somewhat disagree, strongly disagree. }\end{array}$} \\
\hline
\end{tabular}

pertaining to mentorship composition include: informal, M-initiated, duration, and gendersame. The variables pertaining to the initiation of the mentoring relationship were based on a questionnaire item asking respondents to "Please indicate how your relationship with your mentor began." The choices were mutually exclusive, dummy variables indicating (1) if the mentor was assigned through a formal program, (2) if the relationship was informal and initiated by the mentor, and (3) if the relationship was initiated by the protégé. Informal is coded one if the mentorship was formed informally and zero if the mentor was assigned through a formal program. M-initiated is coded one if the mentor initiated the mentorship. The variable Duration indicates the duration of the mentorship using self-reported responses for the year and month the mentorship began and ended. Gendersame is a dummy variable coded one if the mentor and protégé gender are the same.

Four variables measuring the social capital focus of the mentorship are derived from responses to two questionnaire items indicating that "My mentor helped introduce me to influential people in this organization" and "My mentor helped introduce me to influential people outside this organization." Response categories are a four-point Likert scale of agreement. Because we are interested in examining high levels of social capital and mentorship introductions to influential people, we recoded the responses so that one equals strong agreement with the statement and zero is all other responses (somewhat agree, somewhat, disagree, strongly disagree). We then combined the responses to create four dummy variables that are mutually exclusive and indicate if the mentor helped introduce the protégé to (1) influential people inside and outside the organization (social capital [SC]-both); (2) influential people inside the organization (SC-inside); (3) influential people outside the organization (SC-outside); and (4) neither (SC-neither). (See Appendix 2 for details about these measures). These four variables test the social capital focus of the mentorship; however, we are not suggesting that it captures the many aspects of social capital but just one very important one — introductions to influential persons and attendant 
expansion of one's social contacts. An important limitation is that these measures do not provide information about the quality or utility of the introductions.

We include three control variables. The dummy variable, Female, is coded one if the respondent is female. The second control, endyear, indicates the year the mentorship ended. ${ }^{3}$ We also control for external social activities with the variable, Total Civic Activities, which is an additive index comprised of responses to a series of dummy variables listing organizations or groups to which the respondent might belong. This control is useful inasmuch as it frames the various mentoring social capital dummies. The variable is the sum of all memberships and a partial indicator of the respondent's accumulated external social capital (see Appendix 2 for details).

\section{STATISTICAL APPROACH}

We test our hypotheses by estimating a series of statistical models, all based on multinomial logistical (MNL) regression analysis. Although it would have been acceptable to use binary logit for two of the dependent variables, for consistency of interpretation we used multinomial logical regression for all four. The MNL results and coefficients are identical to binary logit results (for an explanation and proof see Alvarez and Nagler 1995, 1998). Given the increasing popularity of MNL regression analysis, no detailed discussion is required here (the reader unfamiliar with the technique is directed to the following sources: Demaris 1992; Gujarati 2003; Long 1997). This statistical approach is especially appropriate for our research inasmuch as the dependent variables are mutually exclusive, nonordinal categories. At the same time the approach permits use of ordinal or categorical independent variables (factors) and interval-level independent variables (covariates). Our primary interpretation is based on estimated odds ratios or exponential (Exp) beta, which relate predictor variables for a category in relation to their impact on a reference category.

Our analysis is based on a main effects model. The use of the main effects model is the most common approach and the default in many statistical packages and contains the covariate and factor direct effects but no interaction effects. The reason for our reporting a main effects model is that the full factorial model, containing all main effects and factorby-factor interactions, introduces a level of complexity that diminishes interpretability. Moreover, the simpler model seems more appropriate for data having greater construct validity than one would normally expect with even higher quality questionnaire-based data. $^{4}$

There is an important limitation when interpreting multinomial logit results using the the Exp beta coefficient. In many cases, researchers treat the Exp beta as a standard log odds coefficient, interpreting a unit of change in the independent variable's coefficient as a change in the odds of being in the dependent variable category of interest versus the reference group. This is somewhat controversial in the case of MNL. Begg and Gray (1984) provide a widely accepted argument about the robustness of the log odds interpretation of multinomial logit. We follow this conventional practice which many statistical authorities (e.g., Long 1997) find convincing. However, we note that some minority of

\footnotetext{
3 When respondents indicated that the mentorship had not yet ended, we entered an end date of December 2005, the close of the survey.

4 Results from the full factorial models are available upon request.
} 
Table 3

Multinomial Logit Analysis of Mentor Satisfaction

\begin{tabular}{|c|c|c|c|c|}
\hline \multirow[b]{3}{*}{ Variables } & \multicolumn{4}{|c|}{ Mentor satisfaction } \\
\hline & \multicolumn{2}{|c|}{ Lowest Level versus highest level } & \multicolumn{2}{|c|}{ Middle level versus highest level } \\
\hline & $B$ & Exp beta & $B$ & Exp beta \\
\hline Intercept & -5.001 & & -9.986 & \\
\hline Duration & -0.046 & 0.955 & -0.039 & 0.962 \\
\hline Advance & -0.330 & 0.719 & -0.145 & 0.865 \\
\hline Security & -0.105 & 0.900 & 0.064 & 1.066 \\
\hline Civic activities & -0.055 & 0.947 & 0.205 & 1.227 \\
\hline Endyear & 0.003 & 1.003 & 0.005 & 1.005 \\
\hline Gendersame & -0.095 & 0.909 & 0.469 & 1.599 \\
\hline Informal & -0.360 & 0.697 & 0.034 & 1.034 \\
\hline Female & 0.225 & 1.253 & -0.413 & 0.662 \\
\hline M-initiated & -0.535 & 0.586 & -0.299 & 0.741 \\
\hline External & 0.205 & 1.228 & 0.024 & 1.024 \\
\hline SC-both & -3.647 & $0.026 * * *$ & -1.987 & $0.137 * * *$ \\
\hline SC-outside & -1.453 & $0.234^{*}$ & -0.611 & 0.543 \\
\hline SC-inside & -1.502 & $0.223 * * *$ & -0.886 & $0.412^{* *}$ \\
\hline SC-none & $0(\mathrm{~b})$ & & $0(\mathrm{~b})$ & \\
\hline
\end{tabular}

Reference value: highest level of satisfaction. Log likelihood: 464.664. $N=258$.

$*_{p}<.10, * * p<.05, * * * p<.01 ;$ two-tailed test of significance.

observers (e.g., Swait and Louviere 1993) fault the log odds interpretation of Exp beta and the violation which occurs when the respective categories are not truly mutually exclusive and one can be substituted for another (not a violation which applies to our dependent variables).

\section{RESULTS}

Beginning with the assumption that public sector mentoring has a variety of potentially important outcomes, ones not necessarily interrelated in predictable ways, we examined four different outcomes. Only one of the focal outcomes, satisfaction with the mentor, is routinely examined in the "generic" mentoring literature. Three other outcomes, including the number of employees supervised, whether the current job was a promotion, and if the protégé has become a mentor, are rarely examined in the generic literature and have never been the subject of systematic analysis in the public management literature.

The outcomes for satisfaction with the mentor are presented in table $3\left(\chi^{2} 77.5\right.$; significance level .000; Cox and Snell pseudo $R^{2}$.259.) Table 4 provides the results for the model predicting the number of employees supervised $\left(\chi^{2} 79.5\right.$; significance level .008; Cox and Snell pseudo $R^{2} .301$ ). Tables 5 and 6 show the results for the model predicting if the protégé's current position is a promotion from the job immediately preceding it $\left(\chi^{2} 37.9\right.$; significance level .000; Cox and Snell pseudo $\left.R^{2} .136\right)$ and the propensity of protégés to become mentors $\left(\chi^{2} 26.8\right.$, significance level .01; Cox and Snell pseudo $R^{2}$ .196), respectively.

Since we do not specify different hypotheses for each dependent variable we present our results in order of the hypotheses. 
Table 4

Multinomial Logit Analysis of Number Employees Supervised

\begin{tabular}{|c|c|c|c|c|c|c|c|c|}
\hline \multirow[b]{3}{*}{ Variables } & \multicolumn{8}{|c|}{ Number of employees supervised ${ }^{a}$} \\
\hline & \multicolumn{2}{|c|}{$\begin{array}{c}1-5 \text { employees } \\
\text { versus no } \\
\text { employees }\end{array}$} & \multicolumn{2}{|c|}{$\begin{array}{c}\text { 6-10 employees } \\
\text { versus no } \\
\text { employees }\end{array}$} & \multicolumn{2}{|c|}{$\begin{array}{c}\text { 11-20 employees } \\
\text { versus no } \\
\text { employees } \\
\end{array}$} & \multicolumn{2}{|c|}{$\begin{array}{c}20+\text { employees } \\
\text { versus no } \\
\text { employees }\end{array}$} \\
\hline & $B$ & Exp beta & $B$ & Exp beta & $B$ & Exp beta & $B$ & Exp beta \\
\hline Intercept & 81.129 & & 86.768 & & 203.644 & & -138.58 & \\
\hline Duration & 0.185 & $1.203 * * *$ & 0.119 & 1.126 & 0.210 & 1.233 & 0.163 & $1.177 * *$ \\
\hline Advance & -0.194 & 0.823 & 0.259 & 1.295 & 0.186 & 1.204 & 0.606 & $1.833^{*}$ \\
\hline Security & 0.324 & 1.382 & 0.083 & 1.087 & 0.527 & 1.694 & 0.008 & 1.008 \\
\hline Civic Activities & 0.097 & 1.102 & 0.151 & 1.163 & 0.525 & 1.690 & -0.130 & 0.878 \\
\hline Endyear & -0.041 & 0.960 & -0.044 & $0.957^{*}$ & -0.104 & $0.901 *$ & 0.069 & $1.071 *$ \\
\hline Gendersame & -0.436 & 0.647 & -0.188 & 0.828 & -0.074 & 0.929 & -0.385 & 0.680 \\
\hline Informal & 1.299 & $3.666^{* *}$ & 0.596 & 1.816 & 0.469 & 1.598 & 0.961 & $2.614^{*}$ \\
\hline Female & 0.190 & 1.209 & -0.364 & 0.695 & -0.031 & 0.969 & -0.993 & 0.371 \\
\hline M-initiated & 0.583 & 1.791 & 0.556 & 1.744 & 0.667 & 1.948 & 0.737 & 2.089 \\
\hline External & -0.256 & 0.774 & 0.163 & 1.176 & 0.160 & 1.173 & 0.531 & 1.700 \\
\hline SC-both & -0.769 & 0.463 & -0.389 & 0.678 & -2.263 & 0.104 & -1.448 & 0.235 \\
\hline SC-outside & -0.524 & 0.592 & -0.284 & 0.753 & 0.866 & 2.378 & 1.046 & 2.846 \\
\hline SC-inside & -1.247 & 0.287 & -0.329 & 0.719 & 0.417 & 1.517 & 0.334 & 1.397 \\
\hline $\begin{array}{l}{ }^{\mathrm{a}} \text { The median employ } \\
18 \% \text { of respondents } \\
\text { Reference value: no } \\
* p<.10, * * p<.05\end{array}$ & loyees & tisted & $\begin{array}{l}\text { ge is } 0-1 \\
\text { yees. }\end{array}$ & 0. Only 3 . & f respond & & & \\
\hline
\end{tabular}

Table 5

Multinomial Logit Analysis for Career Advancement

\begin{tabular}{lrl}
\hline & \multicolumn{2}{c}{ Current Job a promotion } \\
\cline { 2 - 3 } \multicolumn{1}{c}{ Variables } & \multicolumn{1}{c}{$B$} & Exp beta \\
\hline Intercept & 26.671 & \\
Duration & -0.059 & $0.942^{*}$ \\
Advance & -0.472 & $0.624^{* * *}$ \\
Security & -0.274 & $0.760^{*}$ \\
Civic activities & 0.033 & 1.034 \\
Endyear & -0.014 & 0.986 \\
Gendersame & 0.452 & 1.572 \\
Informal & 0.301 & 1.352 \\
Female & -0.642 & $0.526^{* *}$ \\
M-initiated & 0.214 & 1.239 \\
External & 1.005 & $2.731^{* * *}$ \\
SC-both & 0.246 & 1.279 \\
SC-outside & -0.730 & 0.482 \\
SC-inside & 0.747 & $2.110^{*}$ \\
SC-none & $0(\mathrm{~b})$ & \\
\hline Reference value: promotion $(=1)$. Log likelihood: $277.294 . N=259$. & \\
${ }^{*} p<.10, * * p<.05, * * * p<.01 ;$ two-tailed test of significance. & \\
\hline
\end{tabular}


Table 6

Multinomial Logit Analysis of Protégé-now-Mentor

\begin{tabular}{lrc}
\hline & \multicolumn{2}{c}{ Protégé now a mentor } \\
\cline { 2 - 3 } \multicolumn{1}{c}{ Variables } & \multicolumn{1}{c}{$B$} & Exp beta \\
\hline Intercept & -94.316 & \\
Duration & -0.024 & 0.976 \\
Advance & -0.421 & $.656^{* *}$ \\
Security & 0.392 & $1.479^{*}$ \\
Civic activities & -0.238 & $0.788^{*}$ \\
Endyear & 0.046 & $1.047^{* *}$ \\
Gendersame & 0.041 & 1.042 \\
Informal & 0.666 & 1.947 \\
Female & 0.206 & 1.228 \\
M-initiated & 0.467 & 1.595 \\
External & 0.784 & $2.189^{* *}$ \\
SC-both & -0.198 & 0.820 \\
SC-outside & 0.380 & 1.462 \\
SC-inside & -0.912 & 0.402 \\
SC-none & $0(\mathrm{~b})$ & \\
\hline Rer & -255 &
\end{tabular}

Reference value: now a mentor (1). Log likelihood: 216.892. $N=255$.

${ }^{*} p<.10,{ }^{* *} p<.05, * * * p<.01$; two-tailed test of significance.

\section{Protégé Work Motivation}

Overall, we find support for our first hypothesis that protégés who have higher work motivation will be associated with more positive mentoring outcomes. As one might expect, respondents who report higher advancement motivation are more likely to supervise more than 21 employees, compared to no employees. Security motivation is not significantly related to the number of employees supervised, however; perhaps in line with the interpretation above, managers at the top levels are less interested in job security and more invested in the organization and even the specific position. Second, those who have higher factor scores for advancement motivation are more likely to report that the current job was a promotion, and not a lateral move. Third, we find that advancement motivation is positively related to the current job being a promotion (table 5: Exp beta $\beta=0.624, p<$ $.01)$. Higher scores on security motivation are related to an increased likelihood of reporting that the current job was a promotion (Exp beta $\beta=0.760, p<.10)$. It is possible that those who have become more invested in the organization, in turn, develop a more conservative career orientation in order to earn promotions. Finally, those who report higher advancement motivation $(\operatorname{Exp} \beta=0.656, p<.05)$ and lower security motivation $(\operatorname{Exp} \beta=$ $1.479, p<.10)$ are more likely to now be mentors.

\section{Internal/External Mentor}

We find partial support for our second hypothesis that more positive mentoring outcomes tend to be associated with mentor and protégé being in the same organization. We do not find significant relationships between having an internal mentor and either satisfaction with the mentorship or number of employees supervised. However, we do find that respondents who have a mentor inside the organization are more likely to report that the last job change 
was a promotion. This is likely an independent effect but could possibly relate to cohort effects among the respondents. For example, those respondents in the upper echelons may have mentors who were in the focal organization but are now retired and, thus, reported as external mentors.

We find that respondents who have a mentor internal to the current organization are more than twice as likely to report having external mentors $(\operatorname{Exp} \beta=2.189, p<.01)$. This is not a function of the fact that the relationship ended long ago; indeed those who are not mentors are more likely to have a mentoring relationship that ended more recently.

\section{Same-Gender Mentorships}

The third hypothesis predicted that more positive mentoring outcomes would be associated with relationships in which the genders are matched. Counter to our expectations, we find that having a same-gender mentor does not significantly relate to protégé satisfaction with the mentoring experience. Indeed, the gender match of mentor and protégé is not significantly related to any of the mentoring outcome measures. However, protégé gender is related to promotion. Women are more likely than men to report that their current job was a promotion $(\operatorname{Exp} \beta=0.526, p<.05)$. In all likelihood, this finding relates to institutional and historical factors in public personnel systems. It may be that men, who previously made up a larger percentage of their respective state's governments, are older and more likely to have topped out. It is also possible that state agencies are making conscious efforts to promote women because women, compared to men, have not held equal proportions of higher level positions (despite making significant gains in percentage of public employees at all levels) (Cornwell and Kellough 1994; Kerr, Miller, and Reid 2002; Lewis 1994; Naff 1994). Nonetheless it is notable that female respondents, regardless of the gender of the mentor, are nearly twice as likely as male respondents to report that their current job was a promotion.

\section{Mentorship Duration}

The duration of the mentorship is not significantly related to two of the outcome measures: protégé satisfaction with the mentor and the protégé becoming a mentor. We find slight support for an association between mentorship duration and promotion and the number of employees supervised. Respondents who report mentorships of longer duration, compared to those who report shorter mentorships, are more likely to report that the current job was a promotion (table 5). However, the coefficient size, when taken with the modest significance level, suggests this finding should be interpreted with caution (Exp $\beta$ $=0.942, p<.10$ ). This support for our fourth hypothesis is not pronounced. Nevertheless, the finding that longer mentoring relationships are related to advancement is likely not a function of career length given that the ending year of the mentorship is included in the equation.

Respondents who report having mentorships with a longer duration are more likely to supervise one to five employees than no employees $(\operatorname{Exp} \beta=1.203)$. Second, if the mentorship has been of longer duration, there is a modest increment in the likelihood that the individual will supervise more than 21 employees. The relationship between longer mentoring duration and supervising more employees may be explained by the relative 
newness of formal mentoring programs in government organizations. It is intuitive that senior managers with extensive supervisory responsibilities will have longer tenure in public service and be more likely to have developed mentoring relationships early in their careers - before the 1990s.

In addition to the variable for mentorship duration, we see some significant relationships between mentoring outcomes and the end date of mentorships. Respondents who report that their mentorships ended longer ago are more likely to report supervising either 6-10 or 11-20 employees than to supervising no employees (see table 4). This is not surprising inasmuch as this is likely an indication of a mature career. More interesting are the findings for those who are in the top echelon, supervising more than 21 employees. Unlike the middle categories, there are sharp distinctions here. The group with the highest number of supervised employees (not surprisingly) reports longer enduring mentoring relationships but also a more recent end year. This is perhaps due to the fact that some of the relationships are of particularly long duration (one-third of mentorships in the sample have a duration of more than 5 years; mean mentorship duration is 3 years and 2 months) and have not ended $(21 \%)^{5}$

\section{Informal/Formal Mentor}

We find only slight support for the hypothesis that more positive mentoring outcomes would be associated with informal mentorships. The formal or informal mentorship origins are not significantly related to protégé satisfaction with the mentor, protégé promotion, or the protégé becoming a mentor. We find that protégés in informal mentorships are more likely to supervise one to five employees, compared to none $(\operatorname{Exp} \beta=3.666, p<05)$. However, the modest level of statistical significance indicates this finding should be treated with caution. As table 4 indicates, the median number of employees supervised is six. Perhaps the most interesting case is those who supervise the largest number of employees. Individuals who have been involved in informal mentorships rather than formal mentorships are twice as likely $(\operatorname{Exp} \beta=2.614)$ to supervise more than 20 employees, as compared to zero.

Although we find that being in an informal mentorship compared to a formal mentorship is related to supervising more employees, this relationship may be explained by the organization's size and culture; although we do not have data on this distinction, we would intuitively expect that those in smaller organizations would be less likely to participate in formal mentoring programs (and obviously less likely to have as many employees available to be supervised).

\section{Social Capital Imparted}

One of our central hypotheses is that mentoring outcomes are related to the social capital focus of mentoring relationships. The findings are clear cut: the social capital focus of the mentorship has bearing on both protégé satisfaction and promotion.

5 If the mentoring had not ended, we nonetheless wished to keep the respondent in the database and, thus, we coded the "end" as the date we received the questionnaire. However, we also developed a dummy variable for mentorship "not ended." The not ended variable was significantly and positively correlated with number of employees supervised (interval) and with the dummy variable for the highest number of employees supervised. 
When considering all the factors in the model predicting satisfaction with the mentor, significant and unique variance is explained by the social capital imparted. Specifically, protégés whose mentoring relationships focus on both internal and external social capital, on outside social capital, and inside social capital are all more likely to report higher levels of satisfaction with the mentorship. The Exp beta for SC-both is significant $(p<.001)$ but the magnitude suggests only limited impact. The Exp beta for SC-outside and SC-inside imply a greater impact on satisfaction $(0.234 \text { and } 0.223 \text {, respectively })^{6}$. The findings predicting middle levels of satisfaction show a similar pattern, the exception being that $\mathrm{SC}$-outside is not significant. To summarize, and to provide a more general conclusion, we can say that in those mentoring relationships where little or no significant social capital is provided, there is a strong likelihood that protégés will report negative assessments of their mentor. The implications of these findings are not entirely clear. In particular, it is possible that a social capital focus of any sort suggests a more active and engaged mentoring relationship or perhaps a more multifaceted relationship. It may be that it is this greater breadth of the mentoring relationship that relates to satisfaction rather than the particular focus on social capital. ${ }^{7}$

Respondents who have had mentoring relationships that provide only inside social capital are more likely to report the current job as a lateral move and not a promotion. This may be due, at least in part, to the fact that more lateral moves occur within the organization than across organizations. Among the $25.5 \%$ of respondents who moved laterally into their current position, more than $60 \%$ moved inside the same organization.

The fact that social capital in mentoring relationships does not affect all the mentor outcomes in this study is not perhaps so surprising when we consider that this important element of mentoring is only one aspect of the mentoring relationship. One might expect that having a mentor is more important than the social capital focus. However, after obtaining the above results we ran a simple Pearson $r$ zero order correlation for the entire sample relating a dummy variable "have or have had a mentor" to the outcome variables, promotion and advancement motivation. There are no significant correlations. This seems to imply that there are just too many determinants of the quality of a mentoring experience for social capital to emerge as an important predictor. Factors such as the structure of personnel systems, historical and cohort effects, and agency function probably play a quite large role in determining public sector career outcomes, even if we assume an otherwise homogeneous set of respondents.

Finally, none of the social capital focus variables relate significantly to the protégés having become mentors. However, the protégé's social activities external to the mentorship, measured in terms of total civic activities, increase the likelihood that the protégé will be a mentor. Thus, civic engagement, rather than the social capital imparted in the focal mentoring relationship, may be an important determinant of the transition from protégé to mentor.

6 The coefficients here are negative due to the reference group chosen for the multinomial logit, but in the interest of clarity and avoidance of double negatives our narrative focuses on the positive (reciprocal) case.

7 In an alternative specification of the model, we examined a single social capital content dummy $(0=$ no attention to social capital, 1 = attention to social capital). The results of this simplified analysis did not alter the primary finding that a social capital focus tends to be associated with mentor satisfaction. 


\section{CONCLUSIONS}

Our results must be treated with caution, ${ }^{8}$ but they provide preliminary evidence of the complexity of mentoring outcomes. The findings suggest that the benefits of mentoring are not straightforward and that different outcomes can be expected from different combinations of mentor, protégé, and relationship dynamics. The tendency to simply assume that "mentoring is good" and to give little thought to the particulars needs redress.

We begin by briefly summarizing the findings. First, the idea that the protégé's motivation affects outcomes receives considerable support. Those with higher levels of advancement motivation tend to supervise more employees and are more likely to now be mentors themselves. Doubtless, many characteristics of the protégé affect outcomes and more direct measures of protégé "quality" would in all probability yield interesting results. Regarding the organizational colocation of the mentor and protégé, we find that respondents who have a mentor inside the focal organization, compared to those with external mentors, are more likely to report that the last job change was a promotion and more likely to have become mentors. Although gender is related to promotion, we do not find support for the third hypothesis that gender matching in mentorships is significantly related to any of the mentoring outcomes.

The duration of the mentoring relation does not seem to affect satisfaction with the mentorship, but does relate positively to the current job being a promotion and to the number of employees supervised. Although we expected that being in an informal versus a formal mentoring relationship might have strong effects on outcomes, the only significant effect was that those who had informal mentoring relationships tended to supervise more employees.

Finally, although the specific findings of the social capital focus of mentoring proved complex, the overall finding is straightforward: any mentoring focus on social capital (inside, outside, or both) is associated with a more positive assessment of the mentor and with the current job having been a promotion. But there is no significant relationship to the number of employees supervised.

In general, the findings suggest that one seeking to conduce beneficial effects from mentoring relationships does well to specify the particular beneficial effects of interest. Different configurations of mentoring variables lead to different outcomes. This leads us to suggest that future studies develop hypotheses that are outcome- or benefit specific, something we chose not to do in this provisional study.

Several of the discrete findings from our study have implications for public management and policy. For example, our findings for the gender and gender mix variables are relevant to policy and management since those designing public sector mentoring

8 It is almost always difficult validly to infer causation from surveys and questionnaire-based studies, which are in most instances accurately described as nonequivalent groups; "post-test only" design (Campbell et al. 1966). As is generally the case in such limited designs, we employed statistical controls in an attempt to rule out some obvious rival hypotheses, but in a study of mentoring outcomes the possibility for omitted variables bias is considerable. For example, we cannot know whether mentor satisfaction is affected by a more generalized predisposition of individuals to be optimistic or pessimistic (i.e., broader-based psychological attributes). Similarly, we cannot know whether the number of persons supervised is a function of the variables in the model or owing to characteristics of the respondents' organization, especially organizational function and technology. In light of these limitations, we consider our results in terms of their suggestiveness and implications for future study. As discussed in some detail above, the study is potentially prone to significant selection effects owing to missing data. 
programs often labor over the question of whether to encourage or discourage cross-gender mentorships. In the generic mentoring literature, concerns about cross-gender mentoring, though anecdotal, chiefly point to negative effects (Auster 1984; Berg and Ferber 1983; Hunt and Michael 1983). Our findings do not indicate variance in outcomes based on gender mix between mentors and protégés.

Our findings also provide more detailed information about the relationship between mentoring and promotion in the public sector. We find that respondents that report mentorships of shorter duration and external mentors are less likely to report that the current position is a promotion. This finding indicates that promotion and career advancement in the public sector are not just related to having a mentor but to the location of the mentor and duration of the relationship. If government agencies continue to support mentor programs, they should consider the importance of nurturing internal, long-term mentorships.

Whether or not the mentor is internal or external to the protégé's organization is also an important factor in governing many aspects of social capital imparted. It is important enough to warrant further investigation. We provide some provocative but inconclusive findings about the location of the mentor. It is important to tease out relationships between the mentor's and the protégé's respective job histories, such as the location, number, and types of previous jobs. It seems especially important to determine (which we cannot do with our data) whether the mentor and the protégé were once in the same organization. We would expect very different implications for a mentorship initially involved people in the same organizations inasmuch as this would be an indicator that the relationship was successfully maintained across organizational and spatial barriers, perhaps indicating an especially high level of attraction and commitment between the mentor and the protégé. In addition, we would expect that data about mentors and protégés who were initially in different organizations but who are now in the same organization would enable us to test mentoring as a recruitment tool.

Finally, the findings in this study point to the importance of understanding the relationships between public sector mentoring and social capital. We see that protégé's with higher levels of social capital are more likely to report satisfaction with the mentorship and that protégés in informal mentorships are more likely to supervise a larger number of employees and protégés who report higher external civic activities are more likely to be mentors. These findings point to the importance of protégé attributes and social capital as a determinant of mentoring outcomes. We also find that social capital imparted in the mentorship is not a significant predictor of promotion for the protégé. In the public sector, promotion is often quite dependent on formal, structured career paths and hierarchies, often determined by tenure in the organization. This implies that mentoring may, as a result of this structuring, play a lesser role, compared to private and nonprofit sectors, in advancement within a single organization. However, there is no reason to believe that the formalization of career structures would differentially affect protégé satisfaction with the mentorship.

This initial study of mentoring outcomes in the public sector indicates the importance of controlling for more detailed information about formal mentoring programs including the role of mentor and protégé preferences in the assignment, personnel restrictions within the protégé and mentor organizations, the duration of the formal program, and the possibility that formal mentorships develop into informal mentorships. As we have elsewhere (Bozeman and Feeney 2007) suggested, it is especially important to understand the 
dynamics of public management mentoring; there is no reason to expect that a research literature based almost entirely on analysis of individuals working in private firms will provide nuanced accounts of public management mentoring. Although the social processes of public sector mentoring are in some respects similar to those in the private sector and the "generic" literature, our analysis shows many important differences as well. In particular, the expected or desired outcomes may well differ. This study provides just a snapshot of public sector outcomes but perhaps suffices to demonstrate the need for richer, more variegated longitudinal analyses. If mentoring remains a primary human resources management tool for organizations and a critical career development tool for public managers, then it is well time to move beyond simple "more is better" prescriptions.

\section{APPENDIX 1}

\section{NASP Study Description}

\section{NASP-III History}

Each new edition of the National Administration Studies Project (NASP) aims to increase our empirical knowledge of public management and administration. NASP-III is an attempt to blend the goals of NASP-I and II while addressing a few new themes of its own. NASP-III aims to collect data on public and nonprofit managers. It expands beyond a single state, surveying managers in Georgia and Illinois, but does not have a national focus. Unlike NASP-II, which focused on a single functional agency (health and human services), the NASP-III sample includes managers from agencies and organizations of numerous functions.

\section{NASP-III Study Approach}

The population of managers in Georgia was drawn from the Georgia Department of Audits comprehensive list of state employees who were on state agency payrolls during the fiscal year 2003-04. We removed employees at technical colleges, commissions, authorities, the office of the governor, and institutions from the judicial or legislative branch. In addition, we removed employees at institutions with less than 20 employees. The population included any job titles coded as "director," "coordinator," "officials or manager," and "professionals" under the pay grade of 017 and all individuals with a pay grade of 017 or higher. The resulting population included 6,164 Georgia managers.

The population of managers in Illinois was developed through a Freedom of Information Act request for a list of all state employees designated as either "senior public service administrators" or "public service administrators." This list included information on 5,461 state employees, including name, agency, and county.

\section{Survey Administration}

The survey administration included a precontact letter, Wave I survey with letter, followup postcard mailing, Wave II mailing, follow-up contacts by phone call and email, and a final Wave III mailing. The survey was closed January 1, 2006. We received 549 responses in Wave I, 135 in Wave II, and the remainder in Wave III. 


\section{APPENDIX 2}

\section{Variables: Descriptions and Descriptive Statistics}

\section{Dependent Variables}

Satisfaction with mentor: additive scale of three survey items. Response categories: strongly agree, somewhat agree, somewhat disagree, and strongly disagree.

1. Overall, my mentor has contributed a great deal to my success in this organization.

2. I have a great deal of respect for my mentor's ideas.

3. If I had it to do over again, I would be reluctant to have this person as a mentor.

Scale descriptive statistics: negative affect item was reverse coded. Cronbach's alpha for three variables $=.71$. Range 1-3, mean 2.2821, median 2, standard deviation 0.75028; missing 16, $N=406$. Very satisfied 180 (46.2\%); somewhat satisfied 140 (35.9\%); and unsatisfied $70(17.9 \%)$. Note: Original satisfaction scale was $1-4$ but so few responses (less than $3 \%$ ) were in the "very unsatisfied" range that this category was collapsed into "unsatisfied."

\#Employees: self-reported number of employees supervised, if any. Responses to the number of employees supervised were skewed, ranging from 0 to 1200 , with the highest quantile starting at less than 100 . We created an ordinal variable with the following categories: zero employees supervised, 1-5, 6-10, 11-20, and more than 21 employees supervised. Zero employees 48, 14.3\%; 1-5 employees 92, 27.4\%; 6-10 employees 67, $19.9 \%$; 11-20 employees 60, 17.9\%; and more than 21 employees $69,20.5 \%$; missing 70 , $N=406$.

Promotion: current job was a promotion in current organization. Yes, 228, 56.2\%, missing 0 , $N=406$.

Protégé has been a mentor: Have you ever been a mentor? Yes, 320, 78.8\%, missing 11, $N=406$

\section{Independent Variables}

Internal/external mentor: Was your mentor a member of your current organization? Yes, 271, $66.7 \%$, missing $6, N=406$.

Formal/informal mentor: My mentor was assigned through a formal program. Yes, 102, $26.3 \%$, missing $21, N=406$.

M-initiated informal: The mentor was more active than I was in initiating an informal mentoring relationship. Yes, 157, 40.5\%, missing 21, $N=406$.

P-initiated informal: I was more active than the mentor in initiating an informal mentoring relationship. Yes, 126, 32.5\%, missing 21, $N=406$.

Female: female $186,46 \%$, missing $4, N=406$.

Gendersame: indicates if the gender of the mentor and protégé are the same, or not. Gender of mentor and protégé differ match $268,66 \%$; missing $9, N=406$. 
Mentorship duration and endear: Please indicate the period in which you were in this mentoring relationship: year and month the mentorship began and ended.

1. Month mentoring began: mean 6.19, median 6, standard deviation 3.5, range 1-12. Missing 61, mentored sample $N=406$.

2. Year mentoring began: mean 1991.61, median 1994, standard deviation 10247, range 1966-2005. Missing 26, mentored sample $N=406$.

3. Month mentoring ended: mean 7.21, median 7, standard deviation 3.415, range 1-12. Missing 129, mentored sample $N=406$.

4. Year mentoring ended: mean 1993.95, median 1996, standard deviation 9, range 1967-2006. Missing 107, mentored sample $N=406$.

Total civic activities: Please indicate which of the following organizations you are currently a member, if any. [Check all that apply]: Group membership response categories included: church, synagogue, mosque, or religious organization; political club or political party committees; professional societies, trade or business association, or labor union; service organizations such as Rotary or Lions; youth support groups such as the Girl's and Boy's Club, Little League Parents Association; neighborhood or homeowners' associations; PTA, PTO, or school support groups; groups sports team or club; other.

Additive index: sum of nine dummy variables. Frequencies: no civic activities 20, 4.9\%; one activity $72,17.7 \%$; two activities $105,25.9 \%$; three activities $109,26.8 \%$; four activities 51 , $12.6 \%$; five activities $27,6.7 \%$; six activities $16,3.9$; seven activities 5, 1.2\%; eight activities $1,0.2 \%$; missing $0, N=406$.

1. Social capital focus

2. My mentor helped introduce me to influential people in this organization: strongly agree 142 , somewhat agree 143 , somewhat disagree 51 , strongly disagree 58 , mean 2.94, median 3, standard deviation 1.034, missing 12, $N=406$. Recoded inside introductions: yes 142, no 252.

3. My mentor helped introduce me to influential people outside this organization: strongly agree 122 , somewhat agree 109 , somewhat disagree 101 , strongly disagree 62. Mean 2.74, median 3, standard deviation 1.063, missing 11, $N=406$. Recoded outside introductions: yes 122, no 272.

Recoded dummy variables: the items had the same four-point scale, strongly disagree $=1$, disagree somewhat $=2$, agree somewhat $=3$, and strongly agree $=4$. The dummy variables were recoded as $4=1$ and all else $=0$. The reason for this approach was partly empirical: (1) truncating at strong agreement smoothed skewed distributions, (2) somewhat agree and somewhat disagree responses behaved in almost all associations more similarly to one another than to strong agreement, and (3) we were interested in examining high levels of social capital and introductions to influential people because casual work life results in most acquaintance introducing one another to a few other persons, even if there is no mentor-protégé relationship, and focusing only on strong agreement responses seemed a conservative test, compared to either adding all responses or constructing dummy variables for all responses. We then used the two dummy variables for 
inside and outside social capital to create four mutually exclusive measures for both inside and outside social capital, inside only social capital, outside only social capital, and neither.

1. Neither: yes, $221,54.4 \%$, missing 12 , valid $=394, N=406$.

2. Inside: yes, $143,35.2 \%$, missing 12 , valid $=394, N=406$.

3. Outside: yes, $122,30 \%$, missing 11 , valid $=395, N=406$.

4. Both: yes, $92,22.7 \%$, missing 12 , valid $=394, N=406$.

Security motivation and advancement motivation: developed from a factor analysis of work motivation items drawn from questionnaire item: We are interested in the factors that motivated you to accept a job at your current organization. Please indicate the extent to which the factors below (some personal, some family, some professional) were important in making your decision to take a job at your current organization.

1. Opportunity for advancement within the organization's hierarchy: very important 138, somewhat important 189 , somewhat unimportant 41 , not at all important 36 , missing 2 .

2. Job security: very important 19 , somewhat important 33 , somewhat unimportant 128 , not at all important 224, missing 2.

3. The organization's pension or retirement plan: very important 196, somewhat important 46, somewhat unimportant 141, not at all important 21, missing 2.

4. Desire for increased responsibility: very important 134 , somewhat important 191, somewhat unimportant 48, not at all important 28, missing 5.

5. Benefits (medical, insurance): very important 219 , somewhat important 137 , somewhat unimportant 30, not at all important 18 , missing 2 .

6. Few, if any, alternative job offers: very important 33, somewhat important 102 , somewhat unimportant 98, not at all important 166, missing 7.

\section{REFERENCES}

Allison, Paul D. 2001. Missing data. Thousand Oaks, CA: Sage Publishing.

Alvarez, R. Michael, and Jonathan Nagler. 1995. The spatial model and specification of choice models. Society for political methodology working paper series. St Louis, MI: Washington Univ.

Alvarez, R. Michael, and Jonathan Nagler. 1998. When politics and models collide: Estimating models of multiparty elections. American Journal of Political Science 42:55-96.

Aryee, Samuel, and Yue Chay. 1994. An examination of the impact of career-oriented mentoring on work commitment attitudes and career satisfaction among professional and managerial employees. British Journal of Management 5:241-49.

Auster, Donald. 1984. Mentors and protégés: Power-dependent dyads. Sociological Inquiry 54 (2): $142-53$.

Baker, Wayne E. 1990. Market networks and corporate behavior. American Journal of Sociology 96:589-625.

Baugh, S. Gayle, and Ellen A. Fagenson-Eland. 2004. Boundaryless mentoring: An exploratory study of the functions provided internal versus external organizational mentors. Journal of Applied Social Psychology 35:939-55. 
Begg, Colin, and Robert Gray. 1984. Calculation of polychotomous logistic regression parameters using individualized regressions. Biometricka 71 (1): 11-8.

Berg, Helen, and Marianne Ferber. 1983. Men and women graduate students: Who succeeds and why? Journal of Higher Education 54 (6): 629-48.

Bourdieu, Pierre. 1985. The three forms of capital. In Handbook of theory and research for the sociology of education, ed. J. G. Richardson, 241-58. New York: Greenwood Press.

Bozeman, Barry, and Mary K. Feeney. 2007. Toward a useful theory of mentoring. Administration and Society 39:719-39.

Bozionelos, Nikos. 2004. Mentoring provided: Relation to mentor's career success, personality, and mentoring received. Journal of Vocational Behavior 64 (1): 24.

Burke, Ronald J., and Carol A. McKeen. 1997. Benefits of mentoring relationships among managerial and professional women: A cautionary tale. Journal of Vocational Behavior 51 (1): 43-57.

Burt, Ronald S. 1997. A note on social capital and network content. Social Networks 19:355-73. 2000. The network structure of social capital. Research in Organizational Behavior (pre-print), ed. R. I. Sutton, and B. M. Staw, 22. Greenwich, CT: JAI Press.

Campbell, Donald T., Julian Stanley, and N. L. Gage. 1966. Experimental and quasi-experimental designs for research. Chicago, IL: Rand McNally.

Chao, Georgia T. 1997. Mentoring phases and outcomes. Journal of Vocational Behavior 51 (1): 15-28.

Chao, Georgia T., Pat M. Walz, and Philip D. Gardner. 1992. Formal and informal mentorships: A comparison on mentoring functions and contrast with non-mentored counterparts. Personnel Psychology 45:619-37.

Coleman, James S. 1988. Social capital in the creation of human capital. The American Journal of Sociology, Supplement: Organizations and Institutions: Sociological and Economic Approaches to the Analysis of Social Structure 94:S95-120.

Collins, Eliza G. C., and Patricia B. Scott. 1978. Everyone who makes it has a Mentor. Harvard Business Review 56 (4): 89-110.

Cornwell, Christopher, and J. Edward Kellough. 1994. Women and minorities in federal-government agencies - Examining new evidence from panel-data. Public Administration Review 54:265-70.

Demaris, Alfred. 1992. Logit modeling: Practical applications. Newbury Park, CA: Sage Publications.

Eby, Lillian. T. 1997. Alternative forms of mentoring in changing organizational environments: A conceptual extension of the mentoring literature. Journal of Vocational Behavior 51 (1): 125-44.

Eby, Lillian. T., and Tammy D. Allen. 2002. Further investigation of protégés' negative mentoring experiences patterns and outcomes. Group and Organization Management 27 (4): 456-79.

Eby, Lillian. T., Jaime Durley, Sarah Evans, and Belle Ragins 2006. The relationship between short-term mentoring benefits and long-term mentor outcomes. Journal of Vocational Behavior 69 (3): 424-44.

Fagenson, E. A. 1989. The mentor advantage: perceived career/job experiences of protégés versus non-protégés. Journal of Organizational Behavior 10:309-20.

Fagenson-Eland, Ellen A., Michelle K. Marks, and Karen L. Amendola. 1997. Perceptions of mentoring relationships. Journal of Vocational Behavior 51 (1): 29-42.

Feeney, Mary K. 2007. Sector perceptions among state-level public managers. Journal of Public Administration Research and Theory doi: 10.1093/jopart/mum025.

Fox, Richard L., and Robert A. Schuhmann. 2001. Mentoring experiences of women city managers -Are women disadvantaged? American Review of Public Administration 31:381-92.

Friedkin, Noah E. 1978. University social-structure and social networks among scientists. American Journal of Sociology 83:1444-65.

Gilbert, Lucia A. 1985. Dimensions of same-gender student faculty role-model relationships. Sex Roles 12 (1-2): 111-23.

Godshalk, Veronica M., and John J. Sosik. 2003. Aiming for career success: The role of learning goal orientation in mentoring relationships. Journal of Vocational Behavior 63 (3): 417.

Green, Stephen G., and Talya N. Bauer. 1995. Supervisory mentoring by advisers-Relationships with doctoral-student potential, productivity, and commitment. Personnel Psychology 48 (3): 537-61.

Gujarati, Damordar N. 2003. Basic econometrics. 4th ed. Boston, MA: McGraw Hill. 
Heimann, Beverly, and Khushwant Pittenger. 1996. The impact of formal mentorship on socialization and commitment of newcomers. Journal of Managerial Issues 8 (1): 1-15.

Hezlett, Sarah, and Sharon K. Gibson. 2007. Linking mentoring and social capital: Implications for career and organization development. Advances in Developing Human Resources 9 (3): 384-412.

Hunt, David M., and Carol Michaels.1983. Mentorship - A career training and development tool. Academy of Management Review 8:475-85.

Hurley, Amy, and Ellen A. Fagenson-Eland. 1996. Challenges in cross-gender mentoring relationships: Psychological intimacy, myths, rumors, innuendos, and sexual harassment. Leadership and Organization Development Journal 17:42-9.

Johnston, William, and Arnold Packer. 1987. Workforce 2000: Work and workers for the 21st Century. Washington, DC: Hudson Institute.

Kelly, Rita Mae, Mary E. Guy, Jane Bayes, Georgia Duerst-Lahti, Lois L. Duke, Mary M. Hale, Cathy Johnson, Amal Kawar, and Jeanie R. Stanley. 1991. Public managers in the states: A comparison of career advancement by sex. Public Administration Review 51:402-12.

Kerr, Brinck, Will Miller, and Margaret Reid. 2002. Sex-based occupational segregation in U.S. state bureaucracies, 1987-97. Public Administration Review 62:412-23.

Klauss, Rudi. 1981. Formalized mentor relationships for management and executive development programs in the federal government. Public Administration Review 41:489-96.

Kram, Kathy E. 1985. Mentoring at work: Developmental relationships in organizational life. Glenview, IL: Scott Foresman.

Lewis, Gregory. B. 1994. Women, occupations, and federal-agencies - Occupational mix and interagency differences in sexual inequality in federal white-collar employment. Public Administration Review 54:271-6.

Lin, Nan. 1999. Building a network theory of social capital. Connections 22 (1): 28-51.

Long, J. Scott. 1997. Regression models for categorical and limited dependent variables. Thousand Oaks, CA: Sage Publications.

Loury, Glen. 1977. A dynamic theory of racial income differences. In Women, minorities, and employment discrimination, ed. P. A. Wallace and A. M. La Mond, 153-86. Lexington, MA: Lexington Books.

Mullen, Ellen J. 1994. Framing the mentoring relationship as an information exchange. Human Resource Management Review 4:257-81.

Naff, Katherine C. 1994. Through the glass ceiling-Prospects for the advancement of women in the federal civil-service. Public Administration Review 54:507-14.

Noe, Raymond A. 1988. An investigation of the determinants of successful assigned mentoring relationships. Personnel Psychology 41 (3): 457-79.

Portes, Alejandro. 1998. Social capital: Its origins and applications in modern sociology. Annual Review of Sociology 24:1-24.

Ragins, Belle Rose. 1997a. Antecedents of diversified mentoring relationships. Journal of Vocational Behavior 51 (1): 90-109. . 1997b. Diversified mentoring relationships in organizations: A power perspective. Academy of Management Review 22:482-521.

1989. Barriers to mentoring: The female manager's dilemma. Human Relations 42:1-22.

Ragins, Belle Rose, and D. McFarlin. 1990. Perception of mentor roles in cross-gender mentoring relationships. Journal of Vocational Behavior 37:321-39.

Ragins, Belle Rose, John L. Cotton, and Janice S. Miller. 2000. Marginal mentoring: The effects of type of mentor, quality of relationship, and program design on work and career attitudes. Academy of Management Journal 43:1177-94.

Ragins, Belle Rose, and Terri Scandura, A. 1997. The way we were: Gender and the termination of mentoring relationships. Journal of Applied Psychology 82:945-53.

Roche, Gerald R. 1979. Much ado about mentors. Harvard Business Review 57 (1): 14-8.

Rubin, Donald B., and Nathaniel Schenker. 1986. Multiple imputation for interval estimation from simple random samples with ignorable nonresponse. Journal of the American Statistical Association 81:366-74. 
Russell, Joyce E. A., and Danielle M. Adams. 1997. The changing nature of mentoring in organizations: an introduction to the special issue on mentoring in organizations. Journal of Vocational Behavior 51 (1): 1 .

Scandura, Terri A. 1992. Mentorship and career mobility-An empirical-investigation. Journal of Organizational Behavior 13 (2): 169-74.

Scandura, Terri A., and B. R. Ragins. 1993. The effects of sex and gender role orientation on mentorship in male-dominated occupations. Journal of Vocational Behavior 43 (3): 251.

Scandura, Terri A., and C. A. Schriesheim. 1994. Leader-member exchange and supervisor career mentoring as complementary constructs in leadership research. Academy of Management Journal 37:1588-602.

Scandura, Terri A., and R. E. Viator. 1994. Mentoring in public accounting firms - An analysis of mentor protégé relationship, mentorship functions, and protégé turnover intentions. Accounting Organizations and Society 19 (8): 717-34.

Swait, Joffre, and Jordan Louviere. 1993. The role of the scale parameter in the estimation and comparison of multinomial logit models. Journal of Marketing Research 30 (3): 305-14.

Tepper, Bennett J. 1995. Upward maintenance tactics in supervisory mentoring and nonmentoring relationships. Academy of Management Journal 38:1191-205.

Thomas, David A. 1990. Mentoring and irrationality-The role of racial taboos. Human Resource Management 28 (2): 279-90.

Thomas, David A., and C. P. Alderfer. 1989. The influence of race on career dynamics: Theory and research on minority career experiences. In Handbook of career theory, ed. M. B. Arthur, D. T. Hall, and B. S. Lawrence. Cambridge, MA: Cambridge Univ. Press.

U.S. Office of Personnel Management. 1998. Women in the federal government: A guide to recruiting and retaining. Washington, DC: U.S. Office of Personnel Management Employment Service.

van Emmerik, I. J. Hetty 2006. Gender differences in the creation of different types of social capital: A multilevel study. Social Networks 28 (1): 24-37.

Young, Angela M., and Pamela L. Perrewe. 2000. What did you expect? An examination of careerrelated support and social support among mentors and protégés. Journal of Management 26: 611-32. 